\title{
Editorial
}

\section{On Health, Ageing and Insurance}

\author{
Christophe Courbage ${ }^{\mathrm{a}}$ and Joan Costa-Font ${ }^{\mathrm{b}, \mathrm{c}}$ \\ ${ }^{a}$ The Geneva Association, 53, route de Malagnou, Geneva CH-1208, Switzerland. \\ E-mail: christophe_courbage@genevaassociation.org \\ ${ }^{\mathrm{b}}$ Departament de Teoria Economica, Universitat de Barcelona, 08034 Barcelona, Catalonia, Spain. \\ ${ }^{\mathrm{c}}$ London School of Economics, Cowdray House, Houghton Street, London WC2A 2AE, U.K.
}

The Geneva Papers (2006) 31, 551-556. doi:10.1057/palgrave.gpp.2510106

For the last 7 years, The Geneva Association has been engaged in a new research programme on Health and Ageing, the main objective pursued being to better understand the role of demographics, new technologies and insurance in the management of health risks in society.

This special edition of The Geneva Papers, the third in our bi-annual health and ageing series, is dedicated to two main issues: the impact of an ageing population on health care and health systems, and the role and development of private health insurance markets in managing health risks. This editorial aims at introducing the reader to the areas covered and its policy context so as to clarify, when possible, the major issues at stake.

It is increasingly being recognized that higher standards of living and better access to information and education ${ }^{1}$ give rise to the improvement of the overall health of populations in most industrialized countries. Not only are people living to an older age, but they are also likely to be enjoying healthier lives. Further evidence indicates that part of these health improvements can be attributed to the development in health technology ${ }^{2}$ and to the investment in health care. ${ }^{3}$ Hence, it is important to disentangle the main forces behind the efficiency of health care to produce its intended outcomes, namely the underlying changes in the demographic composition of the population, the role of insurance mechanisms as well as the role of several public or private incentives.

The increase in the number of people living to an older age appears to be a strong driver of the growing health care consumption, even if experts still propose competing theories on how future health expenditure will look like for some areas of health utilization. ${ }^{4}$ In this respect, demographics and social change clearly point towards the expansion of long-term care needs. Reduction of family size and a higher rate of women participation in the labour market displace some appreciable effects on caregiving conditions. ${ }^{5}$ Indeed a large amount of long-term care was informally provided in the past, typically by other family carers, and is now increasingly being provided in return for monetary compensation. Yet, the organization of both the delivery and the

\footnotetext{
${ }^{1}$ Kenkel (1991).

${ }^{2}$ Lichtenberg (2006).

${ }^{3}$ Mathers et al. (2003).

${ }^{4}$ Zweifel et al. (2004).

${ }^{5}$ Wiener et al. (2003).
} 
financing of long-term care is far from straightforward and has to confront intergenerational inefficiencies. ${ }^{6}$ Furthermore, the effects of the development of homebased services and the interaction of social and health care requires an even more important coordination and institutional design. ${ }^{7}$ This makes long-term care more costly and financially demanding, forcing stakeholders to reflect on ways to support inter-generational mechanisms.

The consequence of the ageing phenomenon, coupled with lower fertility rates, is to destabilize the financing of pay-as-you-go health systems. Faced with a shrinking tax base and higher health costs, they are bound to experience increasing difficulties. This has lead third-party payers, and especially insurance systems, to develop measures either to try to reduce costs and/or to improve the efficiency for current levels of heterogeneous sorts of expenditure. Parallel to this, we see the development of private health insurance markets to either complement, substitute or supplement general health insurance systems. ${ }^{8}$ However, the development of the insurance market remains country specific, and it is still not fully understood what an ideal distribution of tasks between the public and private sectors should look like. The examination of these issues speaks directly to the health care financing debate as far as it exerts major implications for the future sustainability of health insurance schemes.

The mechanisms and the function of insurance are at the forefront in explaining health care investment and its effectiveness. Health insurance provides a way to reduce and to distribute the financial risk associated with health care expenditure, by sharing cost either through time or through individuals. Generally speaking, insurance has two main functions, namely to reduce risks through diversification and to aggregate or pool risks in order to better assess the probability of occurrence. ${ }^{9}$ In the case of health risks, a further function of insurance that is often neglected is that of enlarging the set of goods and care accessible to sick and insured persons that would not otherwise be available to the patient. ${ }^{10}$ Health insurance schemes can be financed both publicly and privately. Public health insurance comprises health coverage mainly funded though income-dependent mechanisms such as social insurance contributions, hypothecated taxes or/and general taxation. Private insurance covers a specific set of health services funded through a premium independent of income. In such a case, each individual pays to an insurance company an actuarial risk premium and receives, if sick, full or partial reimbursement of the resulting health care expenditure. The actuarial premium equals the average cost of a group of individuals with the same risk profile. Therefore, the role of insurance is to identify groups of individuals with the same risk profile and to establish an actuarial premium for this risk. The larger the sample size, the more accurate the estimate of the actuarial premium is. Yet, given that premiums set exclusively on the basis of individuals risk can make the premium unaffordable for certain high-risk groups, public authority typically imposes community-rated premiums, that is, complete pooling of premium across risk types.

\footnotetext{
${ }^{6}$ Pauly (1990); Chen (2001).

${ }^{7}$ Norton (2000).

${ }^{8}$ OECD (2004).

${ }^{9}$ Priest (1987).

${ }^{10}$ Nyman (2003).
} 
The development of insurance schemes is confronted with three well-known phenomena resulting from the so-called information asymmetries between insured and the insurer. First of all is the adverse selection or "hidden knowledge phenomenon": when the insurer is not able to differentiate insurance premiums on a risk basis, as a result, insurance becomes relatively expensive for "good risks" and only "bad risks" remain insured. ${ }^{11}$ The second phenomenon is cream skimming, namely a counter selection process that health insurers undertake to select "good risk" consumers within the same premium-risk group. ${ }^{12}$ Finally, there is moral hazard, a phenomenon that corresponds to a behavioural change resulting from an individual's insurance status. ${ }^{13}$ These phenomena are responsible for various forms of deficiency in the optimal coverage of health risks and can limit the extension of health insurance mechanisms. They also constitute a vast area of ongoing research ${ }^{14}$ that aims at finding the most adequate institutional and financial structures for an efficient allocation of risks.

The following pages offer ten contributions from a wide spectrum of perspectives to better assist in understanding some of these issues. Not only theoretical and empirical issues are tackled, but practical aspects and policy implications are dealt with too. All these contributions are illustrated in the light of various health systems and different countries, providing a broad range of analysis.

This volume starts with three papers looking at the consequences of ageing from two different angles. The first paper discusses its relation to the financing of the Spanish health system, and the two others relate to health care in Germany and Japan.

The paper of Gemma Abió Roig is a state-of-the art generational accounting study applied to the Spanish National Health System. This application demonstrates that the viability of the current financing scheme is not guaranteed - as (aggregate) health expenditure is predicted to grow with demographic ageing - and additional taxes would be required over the longer term. The paper also shows that several reforms currently under debate in Spain (higher co-payments, earmarking of alcohol and tobacco taxes) could inform potential proposals elsewhere. Interestingly, the results suggest that hypothecated taxation scarcely brings relief. The clear-cut policy message, therefore, is that more comprehensive interventions are required to make the public health scheme fiscally sustainable.

The paper of Florian Buchner and Jürgen Wasem examines an aspect of health expenditure that is often overlooked in the literature and that has very clear implications for the understanding of health expenditure drivers. It is argued that, in Germany, per capita health expenditure among older people increases at a higher growth rate than among young people, a phenomenon labelled "steeping of health expenditure profiles". Their informative work brings to the fore that steeping undermines existing trust in the functioning and reliability of publicly financed health care, as well as the contract of generations, which stands behind the pay-as-you-go system.

\footnotetext{
${ }^{11}$ Akerlof (1970).

12 Newhouse (1984).

13 Pauly (1968).

${ }^{14}$ See Dionne (2000).
} 
The paper of Tetsuji Yamada, Chia-Ching Chen, Tadashi Yamada, Marianne Fahs and Tetsuo Fukawa addresses the issue of the interactions among different kinds of long-term care in Japan as a way to contain the rising national health care expenditures. Using micro data on the Japanese elderly, they question the basic behavioural determinants of the old age dependent when making choices between nursing home care, community-based formal home care and informal home care. They also look at the incentives provided by the government to develop informal care. Their findings provide a better understanding of the real needs of the elderly and clarify their decision-making behaviours. It also suggests various alternatives in terms of long-term care, as a means of coping with the problem of a rapidly growing public health care expenditure in Japan.

The following set of papers is concerned more specifically with private health insurance in relation to either public health insurance or health care expenses, using Ireland, Spain and the U.S. as illustrations.

At a time of growing interest in the use of private mechanisms to finance health care, analysis of the relationship between public and private health insurance - in particular, the impact of private health insurance on the performance of the public system - should be of considerable use to policy analysts and policymakers. The paper of Brian Nolan on the interaction between private and public funding is thus welcomed and clarifies some of these implications. It adds to the literature by raising awareness of the importance of understanding the context in which the Irish market for private health insurance is situated, by highlighting how the role of private health insurance in Ireland has changed over time and by linking analysis of the market to stated public policy goals.

Also, based on the interaction between private and public health insurance, though drawing from econometric methods, the paper of Joan Costa-Font and Mirea JofreBonet examines empirically the association between the purchase of private health insurance and the satisfaction with the National Health System in Spain. Their findings indicate that NHS satisfaction and private health insurance are negatively correlated, suggesting that there is substantial scope for reform in the Spanish health system. Furthermore, they show that when taking into account this association, perceived quality of NHS care seems to explain the demand for private health insurance, but not NHS satisfaction. Purchase of private health insurance may indicate that the NHS is failing to satisfy the demand for differentiated amenities from a heterogeneous population

The paper of Marin Gemmill, Joan Costa-Font and Panos Kanavos addresses another sensitive question regarding health insurance, which is that of the heterogeneous impact of insurance coverage, whether public or private, in various sources of health expenditure in the U.S. using data for 1996-2002. They develop an econometric methodology that accounts for sample selection, endogeneity and heterogeneity. Their results suggest different policy implications depending on the type of expenditure examined. In particular, the effect of ageing and insurance are heterogeneous across the health expenditure type. Furthermore, drug spending may not be related to the expansion of public coverage while one accounts for insurance coverage, and income may even exert a negative impact on most elements of health spending. 
The next two papers address the phenomenon of risk selection in markets for private health insurance with community-rated premiums, first in the case of Germany, then of Australia.

The paper of Johann Eekhoff, Markus Jankowski and Anne Zimmermann looks at how to overcome the trade-off between the possibility of enforcing long-term insurance contracts on the one hand, and the danger of risk selection on the other. The paper outlines the current discussion on the transferability of ageing provisions in the private health insurance market in Germany and provides an overview of the ongoing discussions regarding the feasibility of having more intense competition in Germany. It proposes portable risk-adjusted ageing provisions as a solution for risk selection in community-rated frameworks in Germany and elsewhere.

Still on the subject of the private health insurance market, but within the context of the Australian health system, the paper of Luke Connelly and Shelton Brown considers the problem of inducing low-risk individuals to buy private health insurance when there is community rating, so that the loss probability that determines the premium is the weighted average of loss probabilities across risk types. They suggest a subsidy profile that obviates adverse selection in private health insurance markets with mandated community rating. This subsidy profile depends on age and health risk. Such analysis provides important information for other countries where community rating is also mandated.

Finally, the last two papers close this volume by showing that the function of health insurance is also to provide access to care that would not be otherwise accessible.

The paper of John Nyman presents an overview of the evolution of the theory of the demand for health insurance. It argues that health insurance provides an important demand-side externality in the sense that it gives consumers access to health care that they otherwise would not have been able to afford to purchase were they not insured. This external benefit is seen as a market failure and represents the prime reason for government intervention to either subsidize the purchase of health insurance or to provide it to all citizens.

The paper of David Dror and John Amstrong offers a very interesting application of some of the ideas developed in Nyman's contribution. Indeed, it addresses the issue of micro health insurance and how it facilitates a way of providing a platform enabling health insurance to work for poor people. They seek to investigate the capital needs to ensure the financial sustainability of micro health insurance units, and examine alternatives able to satisfy these needs. They offer a technical basis for discussion, both among market innovators in the insurance industry and among policymakers of micro health insurance.

All in all, this set of papers provides some important messages for policymakers on how best to plan the financing and the organization of health systems. Concerns are indeed raised about their future sustainability, as briefly explained earlier on. However, solutions to cope with the actual trend seem to emerge as research on the topic develops further and public opinion progressively wakes up to the seriousness of the situation. In particular, there is scope for the development of insurance mechanism solutions based on public and private interactions and a need to further explore the rules and limits of such partnerships in order to avoid costly overlap and missed 
opportunities. The role of The Geneva Papers is to assist the evolution of such a debate and to serve as a rigorous forum to its participants, the aim we had in mind as we edited this volume.

This special issue of The Geneva Papers would not have been possible without the help of external referees, who took the time to evaluate and to review the papers that were submitted to us. It is now time to thank them warmly for their effort. These persons are David Bardey, Howard Bolnick, Holger Bonin, Roland Eisen, Stefan Felder, Marin Gemmill, Stefan Gress, Mireia Jofre-Bonet, Scott Harrington, Marisa Miraldo, Jean-François Outreville, Jaume Puig-Junoy, Ray Rees, Marisol Rodríguez, Jonas Schreyögg, Erik Schut, Sarah Thomson, Birgit Trukeschitz, Gilberto Turati and Raymond Yeung.

Last but not least, we are indebted to all the authors who contributed to this volume and we would like to express to them our deep gratitude. Let us now hope that you will have as much pleasure in reading these articles as we have had in editing this special issue of The Geneva Papers.

\section{References}

Akerlof, G.A. (1970) 'The market for "lemons": Quality uncertainty and the market mechanism', Quarterly Journal of Economics 84(3): 488-500.

Chen, Y.-P. (2001) 'Funding long-term care in the United States: The role of private insurance', The Geneva Papers on Risk and Insurance - Issues and Practice 26(4): 656-666.

Dionne, G. (ed.) (2000) Handbook of Insurance, Boston: Kluwer Academic Publishers.

Kenkel, D. (1991) 'Health behavior, health knowledge, and schooling', Journal of Political Economy 99(2): 287-305.

Lichtenberg, F.R. (2006) The impact of new laboratory procedures and other medical innovations on the health of Americans, 1990-2003: Evidence from longitudinal, disease-level data, NBER Working paper No. 12120.

Mathers, C.D., Murray, C.J., Salomon, J.A., Sadana, R., Tandon, A., Lopez, A.D., Ustun, B. and Chatterji, S. (2003) 'Healthy life expectancy: Comparison of OECD countries in 2001', Australian and New Zealand Journal of Public Health 27(1): 5-11.

Newhouse, J.P. (1984) 'Cream skimming, asymmetric information, and a competitive insurance market', Journal of Health Economics 3(1): 97-100.

Norton, E.C. (2000) 'Long-term care', in A.J. Culyer and J.P. Newhouse (eds.) Handbook of Health Economics, Vol. 1B, Amsterdam: Elsevier Science, pp. 955-993.

Nyman, J.A. (2003) The Theory of Demand for Health Insurance, Stanford, California: Stanford University Press.

OECD (2004) Private Health Insurance in OECD Countries, Paris: OECD.

Pauly, M. (1968) 'The economics of moral hazard: Comment', American Economic Review 58(3): 531-537.

Pauly, M.V. (1990) 'The rational nonpurchase of long-term care insurance', Journal of Political Economy 98(1): 153-168.

Priest, G. (1987) 'The current insurance crisis and modern tort law', Yale Law Journal 96(7): 1521-1590.

Wiener, J.M., Tilly, J. and Evans Cuellar, A. (2003) Consumer-Directed Home Care in the Netherlands, England and Germany, Washington DC: Public Policy Institute.

Zweifel, P., Felder, S. and Werblow, A. (2004) 'Population ageing and health care expenditure: New evidence for the "red herring", The Geneva Papers on Risk and Insurance - Issues and Practice 29(4): $652-666$. 